\title{
Distributed Processing of Sensory Information in the Leech. II. Identification of Interneurons Contributing to the Local Bending Reflex
}

\author{
Shawn R. Lockery and William B. Kristan, Jr. \\ Department of Biology, University of California, San Diego, La Jolla, California 92093
}

\begin{abstract}
Isolated midbody ganglia of the leech Hirudo medicinalis were surveyed for interneurons contributing to the dorsal component of the local bending reflex, i.e., to the excitation of dorsal excitatory motor neurons that follows stimulation of dorsal mechanoreceptors responsive to pressure (P cells). Nine types of local bending interneuron could be distinguished on physiological and morphological grounds-8 paired and 1 unpaired cell per ganglion. Synaptic latencies from sensory neurons to interneurons were consistent with a direct or possibly disynaptic pathway. Connections between interneurons appeared to be rare and hyperpolarization of individual interneurons during local bending produced small but reliable decrements in motor neuron response, suggesting that multiple parallel pathways contribute to the behavior. Paradoxically, most interneurons received substantial inputs from ventral as well as dorsal mechanoreceptors, indicating that interneurons that were distinguished by their contribution to dorsal local bending were, in fact, active in ventral and lateral bends as well. The capacity to detect a particular stimulus and produce the appropriate response cannot be localized to particular types of interneuron; rather, it appears to be a distributed property of the entire local bending network.
\end{abstract}

In response to a moderate mechanical stimulus to the dorsal, ventral, or lateral midbody surface, the leech withdraws from the site of stimulation, a response called local bending (Kristan et al., 1982). The sensory cells ( $T$ and $P$ cells) mediating the reflex respond either singly or in combination. The previous paper (Lockery and Kristan, 1990) showed that single or paired dorsal, ventral, and lateral $P$ cell stimulation produced unique patterns of excitation and inhibition in the motor neurons that accounted for appropriate local bending responses. Input to the local bending motor neurons is polysynaptic (Kristan, 1982), suggesting that interneurons play an essential role in transformation of sensory input to motor output patterns. In one model to explain the 3 types of local bending behavior, individual interneurons are dedicated to detecting activity of particular $\mathrm{P}$ cell pairs and commanding the associated motor neuron responses. In a second model, these 2 functions are distributed

Received Sept. 6, 1989; revised Dec. 27, 1989; accepted Jan. 17, 1990

This work was supported by a NSF Predoctoral Fellowship (S.R.L.) and NIH Research grants NS25916 and MH43396.

Correspondence should be addressed to Shawn R. Lockery. Computational Neurobiology Laboratory, The Salk Institute, Box 85800, La Jolla, CA 92037.

Copyright (C) 1990 Society for Neuroscience $0270-6474 / 90 / 061816-14 \$ 02.00 / 0$ across many interneurons which participate in the detection of more than one $\mathrm{P}$ cell pair and the production of several motor patterns.

To distinguish between the dedicated and distributed processing models, we searched for local bending interneurons and examined their input and output connections. In particular, we sought dorsal local bending interneurons (dorsal LBIs), that is, interneurons contributing to the excitation of dorsal longitudinal muscles produced by excitation of dorsal $P$ cells (PDs). Nine types of interneuron were identified. Hyperpolarization of individual interneurons during sensory stimulation produced small decrements in the local bending response, indicating that many interneurons contributed simultaneously to motor output. With a single exception, all interneurons received input from ventral as well as dorsal $P$ cells. This suggested that the local bending network forms a distributed representation of sensory input; moreover, because they received ventral input, dorsal LBIs were also active during lateral and ventral local bending, suggesting that each interneuron contributes to multiple behaviors in a functionally distributed system.

\section{Materials and Methods \\ Physiology}

Animals, preparation of ganglia, and electrophysiological recording techniques were as described previously (Stuart, 1970; Kristan et al., 1974; Ort et al., 1974; Lockery and Kristan, 1990). Intracellular and extracellular recordings were made from single midbody ganglia (ganglion 8,9 , or 10 ) with the glial sheath removed. The large somata of sensory cells and other neurons of the anterior-lateral glial packets were sometimes excised to improve access to the smaller somata of the interneurons. Penetration of interneurons resulted in an increase in extracellularly recorded motor neuron activity, probably due to injury of the interneuron. Therefore, interneurons were returned approximately to resting potential by injecting hyperpolarizing current until spontaneous motor neuron activity returned to prepenetration levels. In some experiments, the $P$ cell was stimulated extracellulary by a suction electrode fixed to a patch of body wall (Kristan, 1982); otherwise, intracellular stimulation was used. The class of dorsal excitatory motor neurons (DEs) was represented by cell 3 or cell 107; of dorsal inhibitory motor neurons (DIs) by cell 1; of ventral excitatory motor neurons (VEs) by cell 4; of ventral inhibitory motor neurons (VIs) by cell 2 (Muller et al., 1981). Data were recorded on FM tape (Crown-Vetter, model A) or digitized (Apple II, ISAAC interface) and stored on disk.

\section{Synaptic latency}

To measure synaptic latency from a sensory neuron to an interneuron, the sensory cell was activated by a brief current pulse that elicited a single action potential. The oscilloscope, triggered to the stimulus, was photographed, and the latency was measured from the peak of the sensory cell action potential to the onset of the synaptic potential. Several sweeps were superimposed to ensure a reliable measurement. 
A
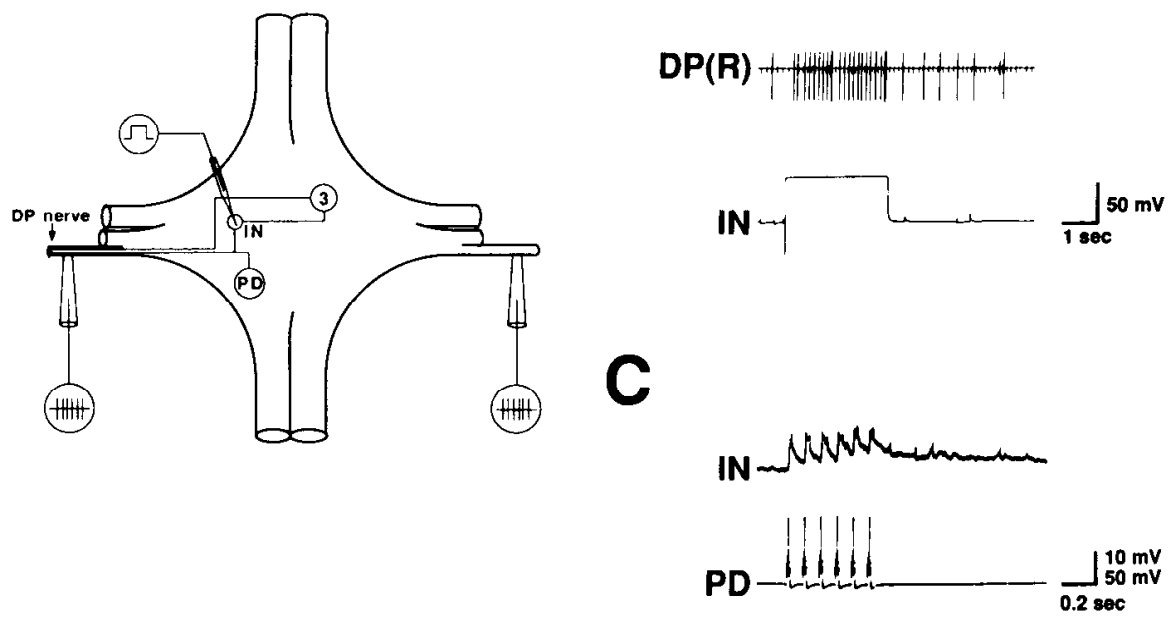

Figure 1. Identification of dorsal local bending interneurons ( $L B I \mathrm{~s})$. $A$, Preparation. The dorsal excitatory motor neuron (cell 3) was recorded extracellularly in the dorsal posterior $(D P)$ nerve. Intracellular recordings were made from interneurons $(I N)$ and the dorsal pressure cell $(P D) . B-C$, Criteria for identification. Interneurons that caused cell 3 action potentials when depolarized $(B)$ and received an excitatory postsynaptic potential from trains of $P D$ impulses (C) were considered dorsal $L B I$ s.

\section{Connections between interneurons}

Pairwise interneuron recordings were made, and each cell in turn was first depolarized then hyperpolarized by current injection. The current pulse was adjusted to an amplitude that was approximately $15 \%$ greater than that which produced a moderate response in cell 3 when the current was depolarizing. To compensate for the fact that interneuron recordings sometimes deteriorated rapidly, results (positive or negative) were accepted only for cases in which the "presynaptic" cell, when depolarized, caused cell 3 to fire, demonstrating that it was still synaptically efficacious.

\section{Necessity tests}

The criteria for identifying an LBI indicated that the input and output connections of a given interneuron are sufficient to contribute to motor output, but they do not demonstrate that the interneuron makes a necessary contribution to motor output. Therefore, 2 types of necessity tests were performed: one with extracellular recording of motor neuron activity, and the other with intracellular recording.

Extracellular. Following identification of a dorsal LBI, the ipsilateral $P$ cell with a dorsal receptive field was stimulated extracellularly with a $(0.5 \mathrm{sec})$ train of impulses (at $10 \mathrm{~Hz})$ which was always sufficient to cvokc local bcnding. In order to minimize the effect of habituation, an alternating, A-B design was used in which the interneuron was hyperpolarized $(1.3-4.0 \mathrm{nA})$ on $A$ trials and not hyperpolarized on $B$ trials. Comparisons were made between successive A and B trials. Intertrial intervals were $10-30 \mathrm{sec}$. Every 5-10 trials, the interneuron was depolarized to determine whether it was still able to fire cell 3. Each necessity test lasted until the interneuron could no longer fire cell 3 (usually less than 20 trials). Cell 3 impulses were counted in a window $0-4.5 \mathrm{sec}$ from the end of the train, as it was not always possible to distinguish cell 3 impulses during the train itself, because of stimulus artifacts and activity of other neurons. Data from the ipsi- and contralateral DP nerve were pooled since depolarization of all interneurons studied increased cell 3 activity on both sides of the ganglion. A cell was considered to make a necessary contribution to the motor neuron response if there were significantly fewer PD-evoked motor neuron impulses on hyperpolarized trials than on the immediately succeeding nonhyperpolarized trials.

Intracellular. A similar A-B design was used, except that the motor neuron was recorded intracellularly, the $P$ cell induced synaptic potentials digitized (at $0.25 \mathrm{kHz}$ ) and the signals averaged. Separate averages were obtained for hyperpolarized and nonhyperpolarized trials. A cell was considered to make a necessary contribution to the postsynaptic response if the average synaptic potential in the motor neuron was greater on nonhyperpolarized trials, as judged by subtraction of the averaged records.

\section{Terminology}

"Ipsilateral" and "contralateral" were defined with respect to locations of cell somata, except in the case of motorneurons, where these terms are defined with respect to the location of the field of innervation.

\section{Statistics}

Averages are means \pm SEM. Significance in necessity tests was assessed using a $t$-test for related measures on the data from pairs of $A$ and $B$ trials.

\section{Results}

Isolated midbody ganglia were searched for interneurons contributing to the dorsal component of dorsal local bending, that is, to contraction of dorsal longitudinal muscles following activation of PDs. Thus, ganglia were surveyed for interneurons that (1) caused impulses in an excitor of DE (cell 3), and (2) werc excited by trains of impulses in PDs sufficient to evoke local bending (Fig. 1). Cells that met both criteria were considered dorsal LBIs.

\begin{tabular}{lll}
\hline $\begin{array}{l}\text { Table 1. } \\
\text { potentials in local bending interneurons } \\
\end{array}$ & $\begin{array}{l}\text { Amplitude of action potentials and P cell induced synaptic } \\
\text { Cell }\end{array}$ & $\begin{array}{l}\text { Synaptic potential } \\
\text { mean (mV) }\end{array}$ \\
\hline 115 & $1.43 \pm 0.14$ & $3.84 \pm 0.50$ \\
125 & $1.74 \pm 0.35$ & $4.57 \pm 1.11$ \\
157 & $4.49 \pm 0.39$ & $2.39 \pm 0.22$ \\
159 & $0.85 \pm 0.12$ & $2.03 \pm 0.35$ \\
161 & $0.88 \pm 0.17$ & $1.97 \pm 0.16$ \\
162 & $6.68 \pm 0.83$ & $4.00 \pm 0.47$ \\
169 & $0.77 \pm 0.08$ & $2.05 \pm 0.32$ \\
212 & $2.40 \pm 0.43$ & $6.37 \pm 1.61$ \\
218 & $0.70 \pm 0.30$ & $7.84 \pm 0.13$ \\
\hline
\end{tabular}

Data were obtained in 5 to 37 cells. 
115
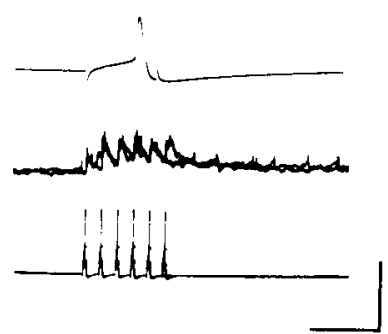

159
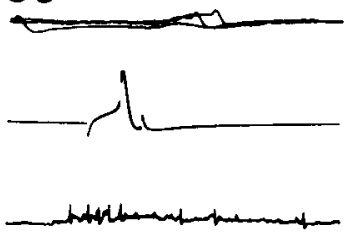

Figure 2. Physiological properties of local bending interneurons. Within each panel, the top trace shows the response of the interneuron to the single PD action potential shown in the second trace. The third trace shows the response to the train of PD impulses shown in the fourth trace. In some traces, 2 or 3 sweeps (several seconds apart) are superimposed to show the extent to which latencies were consistent. Vertical calibration: first and third traces, $10 \mathrm{mV}$ (third trace, cell 115, $20 \mathrm{mV}$ ); second and fourth traces, $100 \mathrm{mV}$. Horizontal calibration: first and third traces, 20 msec; second and fourth traces, 400 msec.
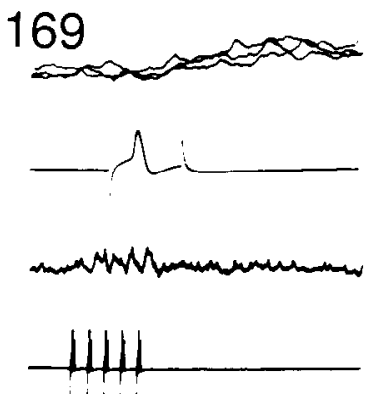
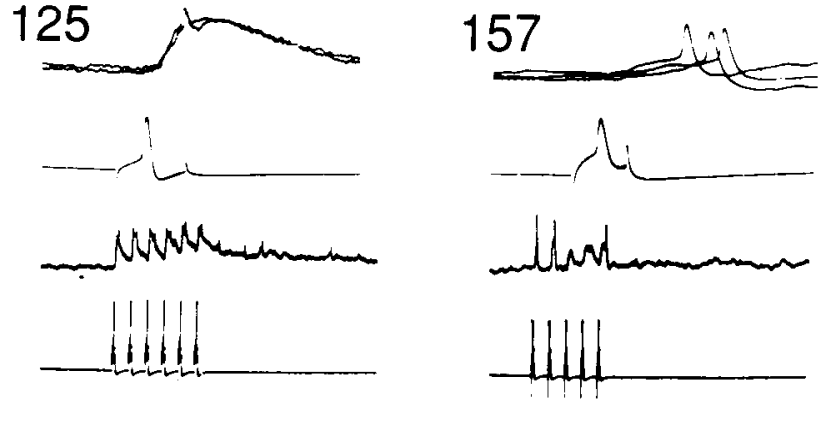

161

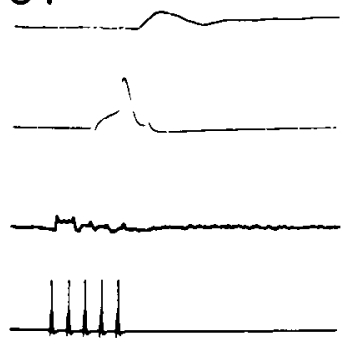

162
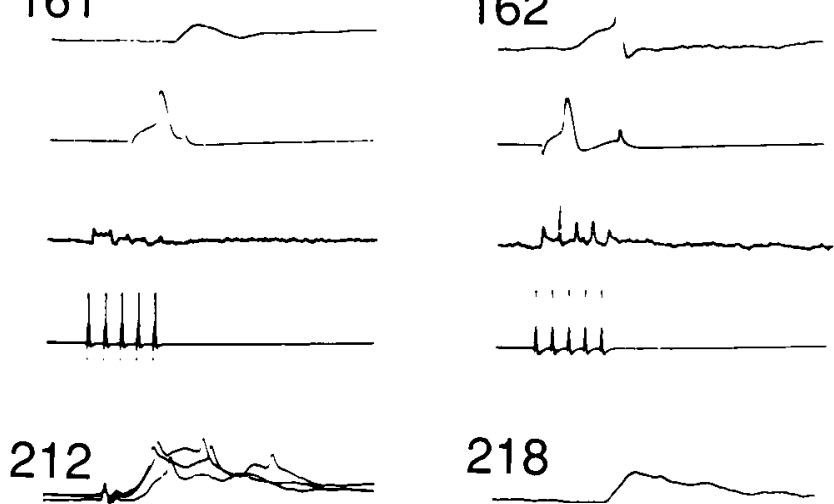

218
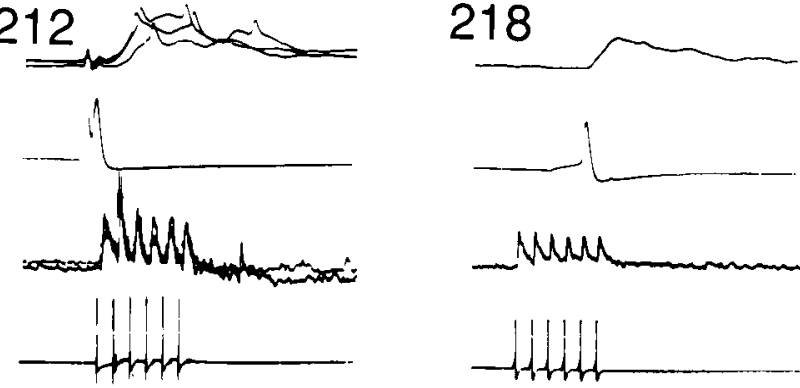

\section{Identification of dorsal LBIS}

The position and soma size of each dorsal LBI found was recorded on a map of the ganglion. After the entire surface of the ganglion was surveyed, one dorsal LBI was reimpaled, filled with the fluorescent dye Lucifer yellow, and drawn using camera lucida. A survey of 73 ganglia yielded a population of 235 cells that qualified as dorsal LBIs. Cells of similar soma size, physiological properties (Fig. 2), and dendritic morphology (Fig. 3) were regularly found in similar locations from one preparation to the next (Fig. 4). There appeared to be only a single representative of each type of cell within each ventral or dorsal hemiganglion since, on a given side of the preparation, we never recorded from cells that were indistinguishable. Most dorsal LBIs appeared to be bilaterally paired because, with one exception, we regularly found cells of similar size and physiological properties at equivalent locations on both sides of the midline. From these comparisons we concluded that there were 9 types of dorsal LBI: 7 on the ventral surface of the ganglion and 2 on the dorsal surface. Eight types occurred as bilateral pairs and the ninth (cell 218) was unpaired. Thus, each ganglion contained 17 dorsal LBIs.

\section{Common features of dorsal LBIs}

No nonspiking interneurons were found, though spikes tended to be small $(<1-7 \mathrm{mV}$, Table 1$)$, suggesting that the soma did

not contain active membrane, a common feature of invertebrate interneurons (Selverston et al., 1976; Susswein and Byrne, 1988), including most in the leech (Thompson and Stent, 1976; Weeks, 1982; Nusbaum et al., 1987). Unitary PSPs, defined as synaptic potentials produced by a single $P$ cell impulse, ranged from 2 to $8 \mathrm{mV}$, and occurred with a short, fixed latency (e.g., Fig. 2, cell 115). Action potentials in the dorsal LBIs did not appear to be necessary for producing an effect on cell 3 : the effect on cell 3 was apparent even with small current injections that were below spike threshold in the interneuron and in pairwise recordings we never saw unitary EPSPs in cell 3 correlated with spikes in the interneuron. Depolarization of dorsal LBIs produced a response in both the ipsi- and contralateral cell 3 , but the effect was generally strongest ipsilateral to the interneuron. Each type of dorsal LBI had at least one axon in the anterior or posterior connective.

\section{Distinguishing characteristics of dorsal LBIs}

The identified neurons differed in the size and shape of their action potentials and in the amplitude and rate of rise of synaptic potentials associated with stimulation of single PD impulses (Fig. 2; Table 1). The synaptic potential produced by trains of PD impulses was also a distinguishing feature; the response of some interneurons (e.g., cell 125) had a rapid and slow component, while the response of other interneurons showed only the rapid (e.g., cell 218) or only the slow (cell 159) component. 


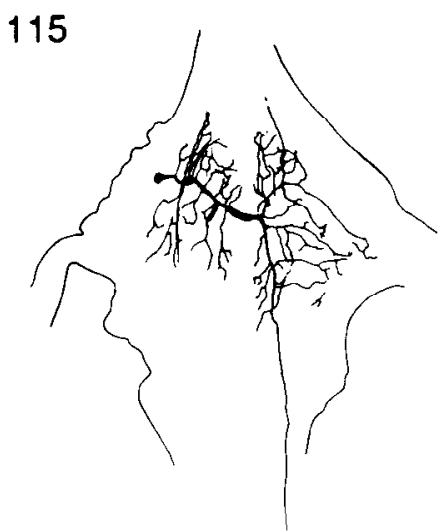

159
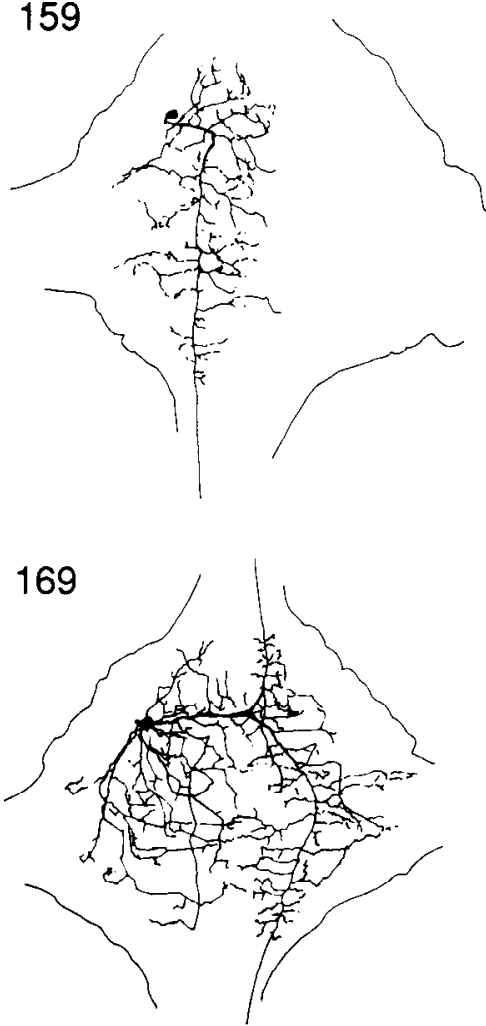

125

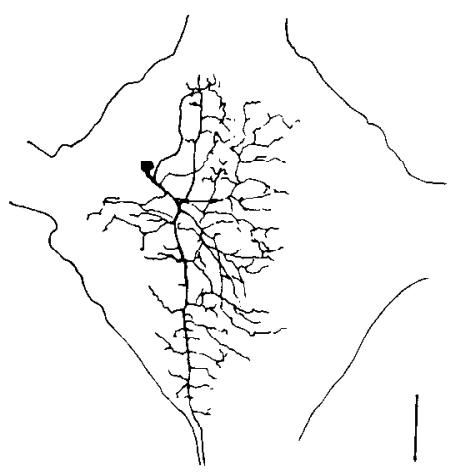

161
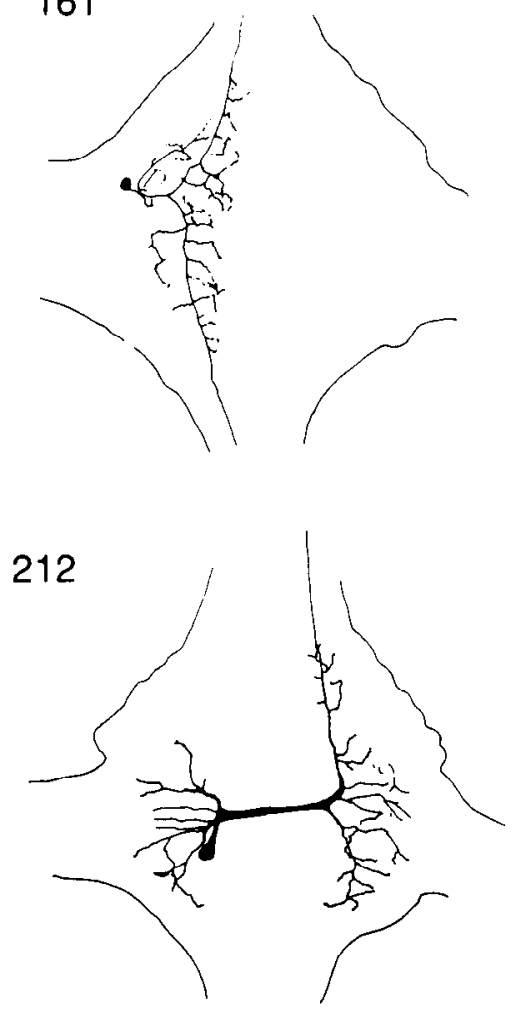

157

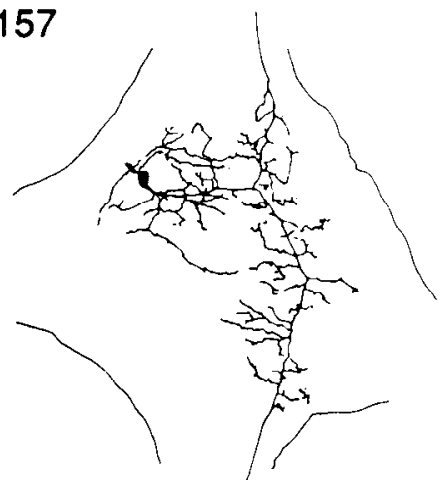

162
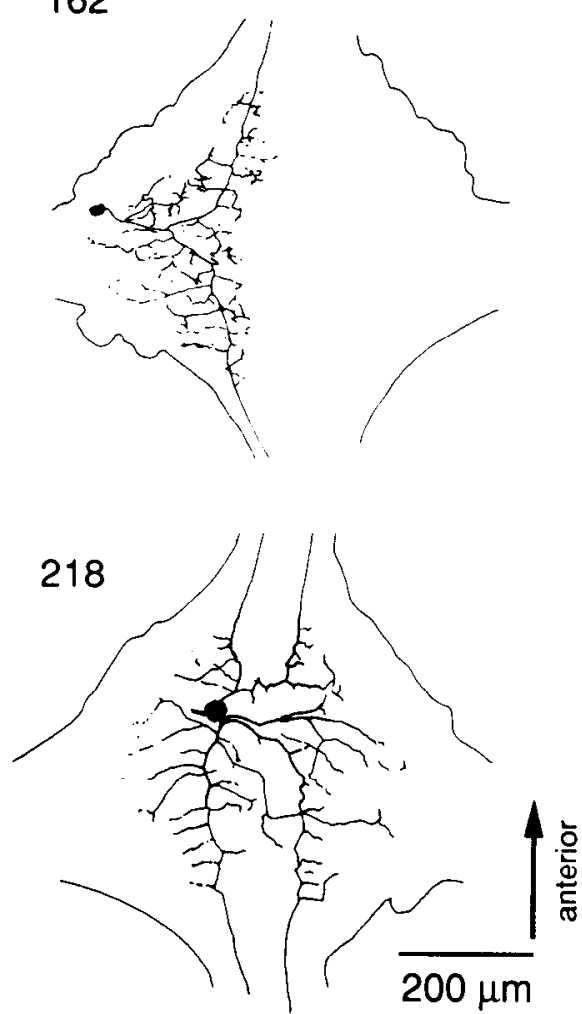

Figure 3. Morphology of local bending interneurons. Camera lucida drawings were made from whole mounts of cells injected ionophoretically with Lucifer yellow. Identifying numbers were assigned according to the most common location of their cell body on a standard map of the ganglion (see Fig. 4).

The identified neurons also differed in morphological features (Fig. 3), including the size and position of somata, the density of dendritic arborization, and the number of axons projecting into the interganglionic connectives. Details of the particular distinguishing characteristics of the 9 types of LBI are given in the Appendix.

\section{Latencies of interneurons and motor neurons}

Previous studies using extracellular stimulation of PD found that synaptic potentials arrived at the dorsal motor neurons with a delay that suggested there was a short, possibly disynaptic pathway from sensory cell to motor neuron (Kristan, 1982). To confirm and extend this result using intracellular stimulation, the latency of synaptic potentials in each type of interneuron, and, for comparison, several types of motor neuron, were de- termined (Fig. 5). Interneurons fell into 3 groups based on similar latencies: a short-latency group (cell 218 only; mean, 0.8 $\mathrm{msec}$ ), an intermediate-latency group (cells 125, 161, 162, and 212; mean, $2.8 \mathrm{msec}$ ), and long-latency group (cells 115,157 , 159 , and 169 ; mean, $5.5 \mathrm{msec}$ ). Motor neurons fell into 2 groups: a short-latency group whose latencies were approximately the same as the long-latency group of interneurons (contralateral VI and ipsilateral DE; mean, $6.5 \mathrm{msec}$ ), and a long-latency group with latencies substantially longer than those of any interneuron (ipsilateral VE, VI, and DI; mean, $10.8 \mathrm{msec}$ ).

\section{Connections between interneurons}

To determine whether serial connections exist in the local bending circuil, pairwise recordings were made from interneurons in different latency groups (Table 2). Connections were tested 


\section{A Ventral}

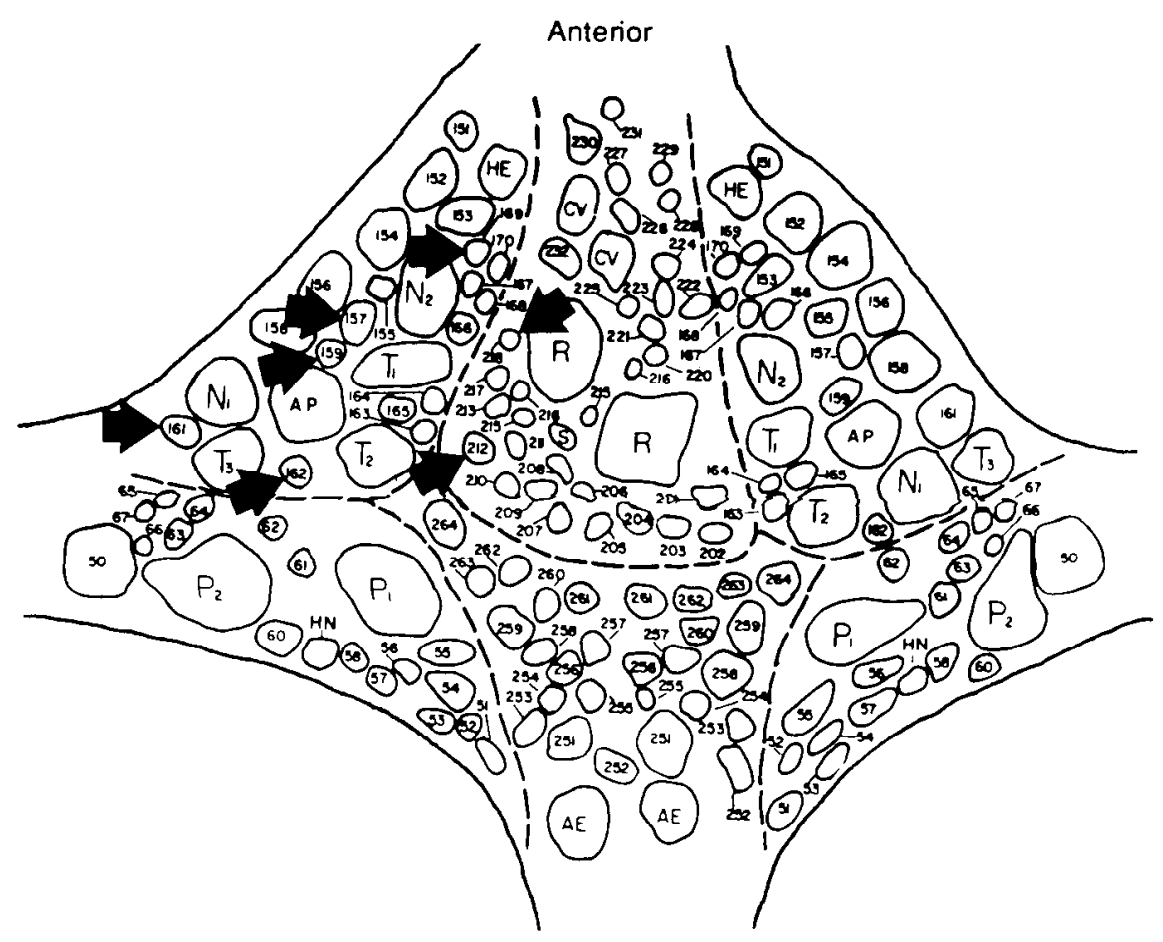

\section{B Dorsal}

Figure 4. Locations of identified local bending interneurons. $A$, Ventral aspect of a midbody ganglion. $B$, Dorsal aspect. Arrows indicate the left member of each bilateral pair of interneurons. Cell 218 is an unpaired cell. Dotted lines indicate margins of glial packets.

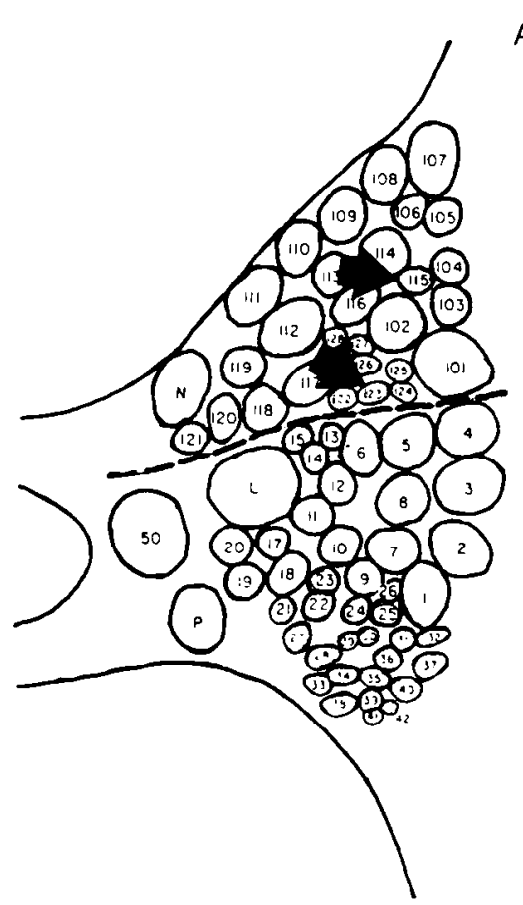

Anterior

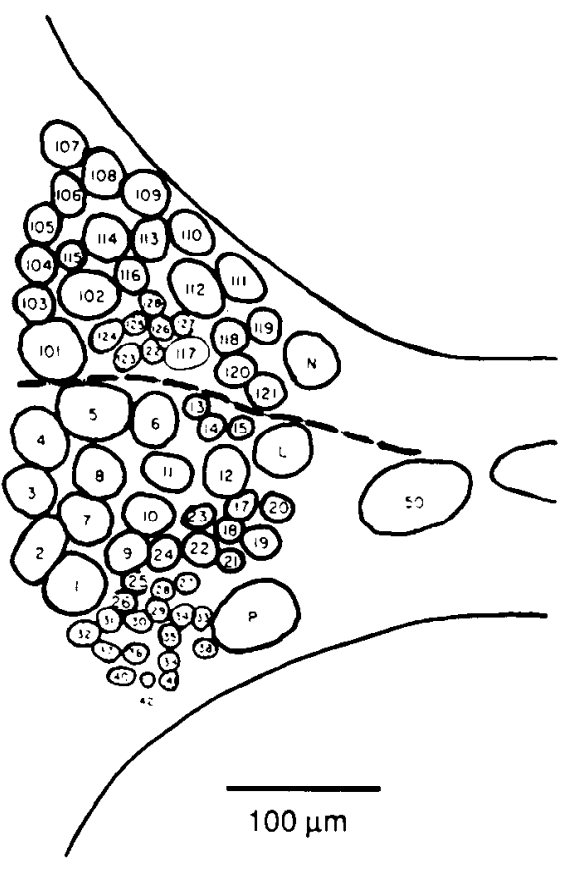

first in the "forward" direction, that is, by depolarizing the cell with the shorter latency. For completeness, connections were then tested in the "backward" direction by injecting current into the other cell. In a smaller number of cases, recordings were made from interneurons in the same latency group to examine the possibility of lateral connections.
The 17 dorsal LBIs in a ganglion yield 136 different possible connections, allowing for both forward and backward connections and compensating for bilateral symmetry and the unpaired cell (218). Because of the difficulties in identifying particular interneuron pairs in the same preparation, and the difficulty of recording simultaneously from the dorsal and ventral surface 


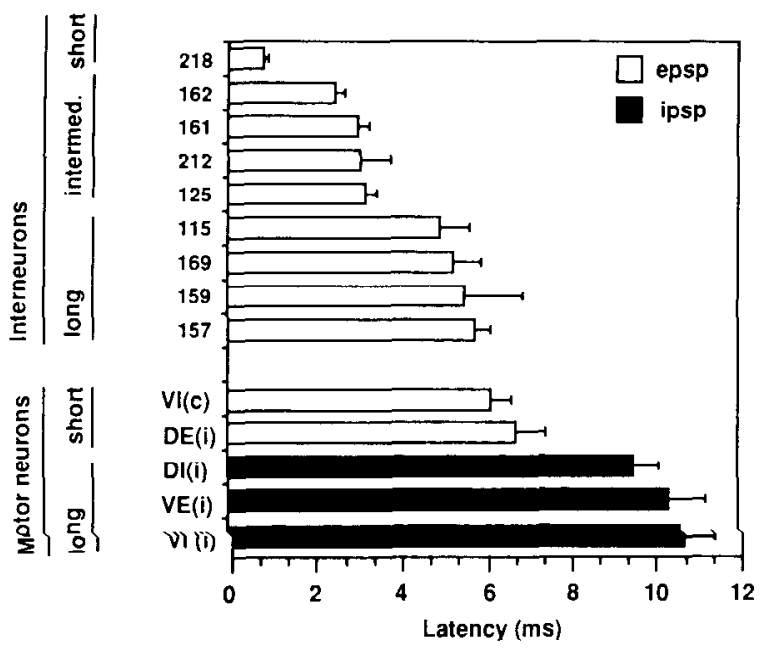

Figure 5. Latency from $\mathrm{PD}$ to each interneuron and several longitudinal muscle motor neurons. Interneurons were ipsilateral to PD; motor neurons were ipsilateral or contralateral as indicated $(c$, contralateral; $i$, ipsilateral). White bars indicate excitatory responses; black bars indicate inhibitory responses. Classification into short, intermediate, and long latency groups is explained in the text.

of the ganglion, we did not examine all possible connections. Thirty-three pairwise recordings were made in which a total of 20 different possible connections were tested. Table 2 lists by latency group all the connections that were tested, together with the number of replications of each test in different preparations. A weak but reliable connection was found between the left and right cell 115 (Fig. 6), which appeared to be linked by a nonrectifying electrical junction since a small amount of current passed from one cell to the other in either direction. No other pairs tested revealed detectable connections.

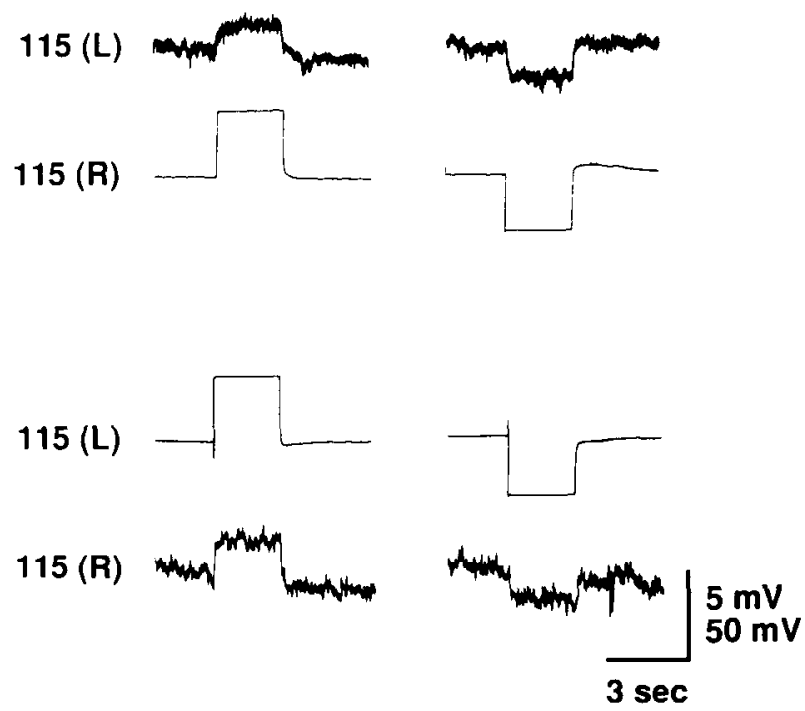

Figure 6. Connection between left and right cells 115 in the same ganglion. Depolarizing, then hyperpolarizing current passed from the right cell 115 to the left (top two rows), and from the left cell 115 to the right (bottom two rows). Current pulses were $\pm 2.6 \mathrm{nA}$. Low gain traces were clipped by the recording apparatus.
Table 2. Tests of connections between local bending interneurons

\begin{tabular}{|c|c|c|c|}
\hline Presynaptic cell & Postsynaptic cell & Connection & $n$ \\
\hline Short & Intermediate & & \\
\hline $218 u$ & 161 & No & 2 \\
\hline $218 u$ & 162 & No & 3 \\
\hline $218 u$ & 212 & No & 1 \\
\hline Short & Long & & \\
\hline $218 \mathrm{u}$ & 157 & No & 1 \\
\hline $218 \mathrm{u}$ & 159 & No & 3 \\
\hline Intermediate & Long & & \\
\hline 161 & $157 \mathrm{i}$ & No & 1 \\
\hline 162 & $157 \mathrm{i}$ & No & 3 \\
\hline Intermediate & Short & & \\
\hline 161 & $218 u$ & No & 1 \\
\hline 162 & $218 \mathrm{u}$ & No & 1 \\
\hline Long & Short & & \\
\hline 157 & $218 \mathrm{u}$ & No & 1 \\
\hline 159 & $218 \mathrm{u}$ & No & 3 \\
\hline 212 & $218 \mathrm{u}$ & No & 1 \\
\hline long & Intermediate & & \\
\hline 157 & $161 \mathrm{i}$ & No & 1 \\
\hline 157 & $162 \mathrm{i}$ & No & 4 \\
\hline 169 & $162 \mathrm{i}$ & No & 1 \\
\hline Intermediate & Intermediate & & \\
\hline 161 & $162 \mathrm{i}$ & No & 1 \\
\hline 162 & $161 \mathrm{i}$ & No & 1 \\
\hline Long & Long & & \\
\hline 157 & $157 c$ & No & 1 \\
\hline 169 & $159 \mathrm{c}$ & No & 1 \\
\hline 115 & $115 \mathrm{c}$ & Yes & 2 \\
\hline
\end{tabular}

Pairwise intracellular recordings were made of interneurons from the same or different latency groups (short, intermediate, or long). Connections were tested by injecting current into one cell (presynaptic) and recording from the other (postsynaptic). Pairs were considered unconnected in the direction tested if no postsynaptic response was seen. Some connections were tested more than once. c, contralateral; i, ipsilateral; u, unpaired.

Extracellular and intracellular tests of the necessity of dorsal $L B I$ for motor neuron responses responsible for local bending

To perform the extracellular tests for necessity, individual interneurons were hyperpolarized on alternate trials of $P$ cell stimulation, and the burst of $P$ cell evoked cell 3 action potentials used as a measure of behavior. Three successive trials of such an experiment, performed on cell 218, are shown in Figure $7 \mathrm{~A}$. $\mathrm{P}$ cell stimulation evoked fewer cell 3 impulses when cell 218 was held hyperpolarized. In 6 of 8 experiments, hyperpolarization of cell 218 significantly reduced the number cell 3 impulses (Table 3). The average (statistically significant) reduction in the number of cell 3 impulses was $33.5 \%$.

The results of hyperpolarizing interneurons from other latency groups are compared with the data on cell 218 in Table 3. Each of the 9 types of interneuron was tested at least once. Of the dorsal LBIs on the ventral surface, at least one exemplar from each latency group appeared to make a contribution to cell 3 responses. However, hyperpolarizing any of these cells produced a smaller effect than did hyperpolarizing cell 218 . No single dorsal LBI thus appeared to be responsible for a large part of the cell 3 response. It is important to note that LBIs, being small and relatively labile under recording conditions, frequently appeared to lose their synaptic efficacy during the 
Figure 7. Effect of hyperpolarization of local bending interneurons on the response of motor neurons to PD stimulation. $A$, Test of interneuron 218 using extracellular recordings of motor neuron response. Upper and lower traces are control recordings of cell 3 action potentials in the DP nerve. In the middle trace, cell 218 was hyperpolarized by current injection. $B-D$, Tests of the indicated interneurons using intracellular recordings from 2 different motor neurons. In each panel, the top trace (control) is the average digitized recording from a dorsal excitor ipsilateral to the interneuron [DE(i)] during elicitation of a train of impulses in the ipsilateral PD. The time of occurrence of each impulse is shown by an arrow. The middle trace (hyperpolarized) is the same, except that the indicated interneuron was hyperpolarized. The lower trace (difference) is the result of subtracting the middle trace from the top trace. A positive difference indicates a detectable excitatory contribution from the interneuron to the postsynaptic response in the motor neuron. Control and hyperpolarized sweeps were recorded on alternated trials. Dorsal excitors used: $B$, cell $3 ; C$, cell $3 ; D$, cell 107. Number of sweeps contributing to each average: $B, 12 ; C, 20 ; D, 6$.
A

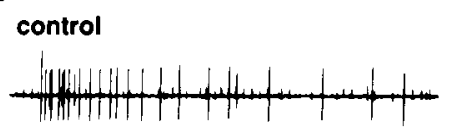

cell 218 hyperpolarized (1.6 nA)

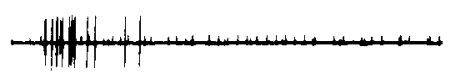

control

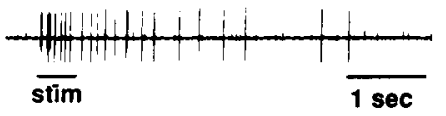

C
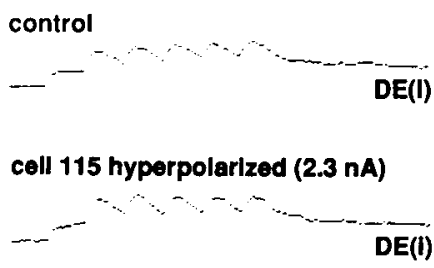

difference

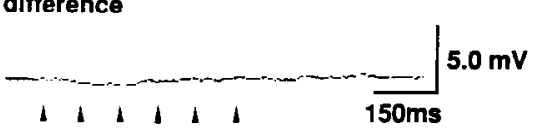

B

control

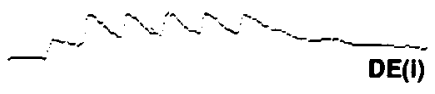

cell 125 hyperpolarlzed (3.8 nA)

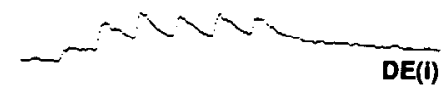

difference

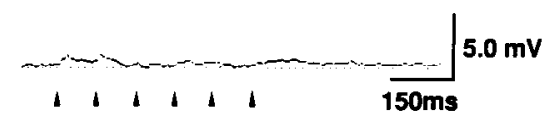

D

control

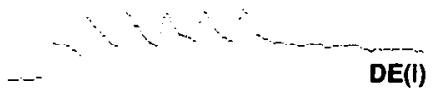

cell 218 hyperpolarized (5.1 nA)

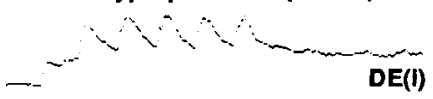

difference

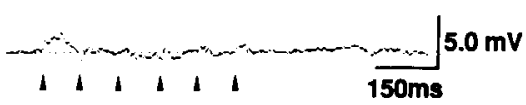

course of a necessity test, as judged by their ability, upon depolarization, to cause cell 3 to fire. To maximize our data set, we did not exclude negative tests where synaptic efficacy was lost, since it was not possible to determine where in the series of trials the loss in efficacy occurred; the necessity test thereby probably underestimated the possible contribution of an interneuron.

The intracellular test of necessity consisted of comparing the size of EPSPs in the motor neuron on trials in which the interneuron was hyperpolarized to those in which it was not. This method, illustrated in Figure $7 B-D$, was practical only for cells 115 and 125 , the 2 dorsal LBIs found on the same surface of the ganglion as cell 3 . The interneuron was hyperpolarized on alternate trials of $P$ cell stimulation, while stimulus-evoked EPSPs were recorded intracellularly from cell 3 . Hyperpolarization of cell 125 produced a small but consistent reduction in the EPSP recorded in cell 3 (Fig. $7 B$ ). The effect was most apparent at the beginning of the synaptic potential. Thus, cell 125 appeared to make a detectable contribution to the excitation of cell 3 during local bending. For cell 115 , by contrast, the difference PSP was flat, or slightly negative, suggesting that hyperpolarizing this cell, if anything, enhanced the effect of $P$ cell stimulation (Fig. 7C). This result is complicated by the fact that hyperpolarization of cell $115(2-3 \mathrm{nA})$ caused a small (1-3 mV) hyperpolarization of cell 3. This level of hyperpolarization, when produced by current injection directly into the soma of cell 3 , caused the $P$ cell-induced synaptic potential to increase in height. Thus, the apparent increase in PSP height on trials in which cell 115 was hyperpolarized may have been due to the hyperpolarization of cell 3. In favorable circumstances, it was possible to obtain pairwise recordings of cell 218 and cell 107 , a dorsal excitatory motor neuron similar to cell 3 (cell 107 usually lies near the lateral margin of the dorsal surface of the ganglion but occasionally appears on the ventral surface), allowing an intracellular necessity test on a third dorsal LBI, cell 218 (Fig. 7D). As with cell 125 , hyperpolarization produced a small but consistent reduction in the initial phase of the motor neuron synaptic potential.

\section{Inputs to local bending interneurons from other $P$ cells}

Pairwise intracellular recordings were obtained between an interneuron and each of the $4 \mathrm{P}$ cells. $\mathbf{P}$ cells were stimulated intracellularly $(1 \mathrm{~Hz}, 0.5 \mathrm{sec})$, and the postsynaptic response recorded in the interneuron. A typical set of recordings from a single interneuron is shown in Figure $8 A$; the response associated with a particular $P$ cell is located in the quadrant of the diagram that corresponds to the quadrant of body surface innervated by that $P$ cell. Responses were quantified as peak synaptic potential and results from at least 3 preparations were averaged for each P cell-interneuron pair (Fig. $8 B$ ). All responses were excitatory, with the largest response usually from the $\mathrm{PD}$ with its soma ipsilateral to the soma of the interneuron. Each interneuron, except cell 161, received substantial inputs from ventral as well as dorsal $\mathrm{P}$ cells, and most interneurons received substantial inputs from all $4 \mathrm{P}$ cells.

\section{Connections from interneurons to motor neurons}

Individual dorsal LBIs were impaled and depolarized by current injection, while recordings were made from each of 8 longitudinal motor neurons (Fig. 9, upper panels). The recording from each motor neuron is shown in the quadrant of the diagram that corresponds to the quadrant of body surface innervated by that 
A

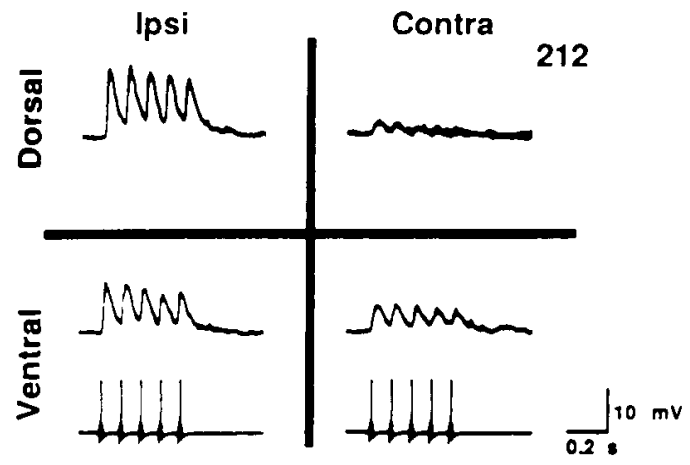

B
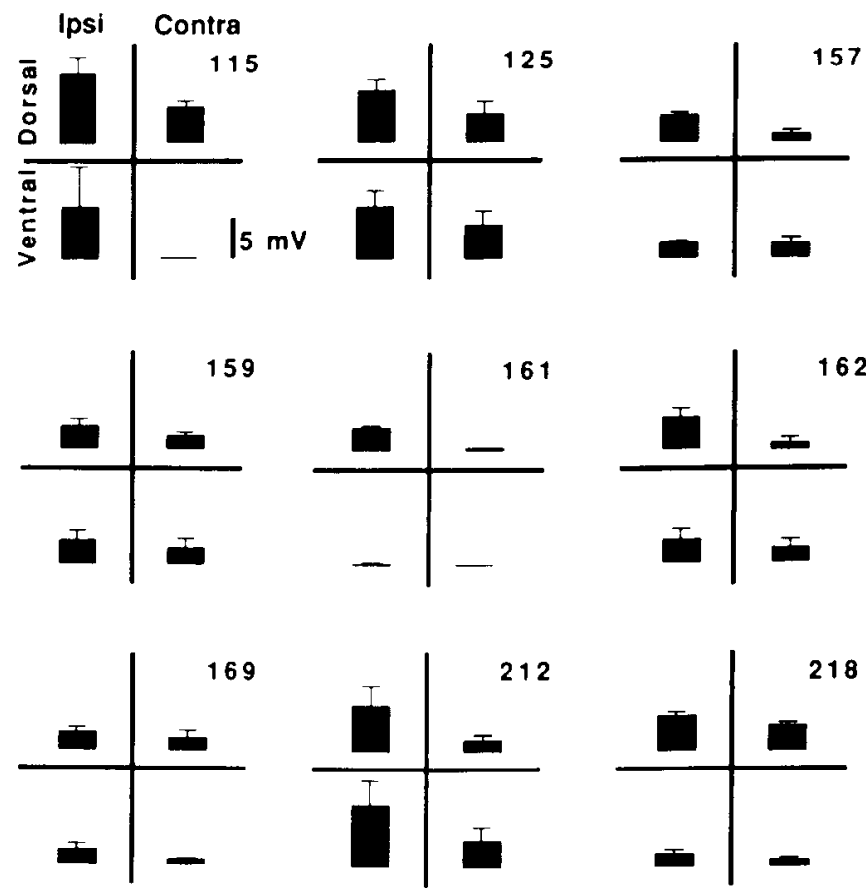

Figure 8. Inputs to interneurons from each $\mathrm{P}$ cell. $A$, Intracellular recording of cell 212 in response to trains of $P$ cell impulses. Each recording is shown in the quadrant location corresponding to the field of innervation of the stimulated $\mathbf{P}$ cell. $B$, Average peak synaptic potential from at least 3 experiments (like the one in $A$ ) for the indicated interneuron.

motor neuron. Within quadrants, excitors are shown on the left, inhibitors on the right.

In determining interneuron-motor neuron connections, we were again limited by the fact that the somata of only 2 of the identified LBIs, cells 115 and 125 , are located on the same side of the ganglion as the somata of the longitudinal motor neurons. Each dorsal LBI tested had a detectable effect on all 8 motor neurons. In general, there was good agreement between the pattern of excitation and inhibition produced by each interneuron and the pattern produced excitation of PD (cf. Lockery and Kristan, 1990, figure $4 A$ ). For cell 115 , the polarity of the average effect was in agreement with the response of all 8 motor neurons to PD stimulation, although there were substantial discrepancies in amplitude. For cell 125, the polarities were in agreement in 6 of 8 motor neurons, and, as with cell 115 , there were considerable discrepancies in amplitude. Where the polarities of the
Table 3. Effect of hyperpolarizing interneurons from different latency groups on the extracellularly recorded response to PD stimulation

\begin{tabular}{llll} 
& & \multicolumn{2}{c}{$\begin{array}{l}\text { Significant reduction in } \\
\text { number of action potentials }\end{array}$} \\
\cline { 3 - 4 } Latency group & $\begin{array}{l}\text { Number } \\
\text { tested }\end{array}$ & Number & $\begin{array}{l}\text { Mean percent } \\
\text { reduction }\end{array}$ \\
\hline Short & 8 & 6 & $33.51 \pm 6.61$ \\
Intermediate & 7 & 2 & $19.47 \pm 0.78$ \\
Long & 4 & 1 & 24.49 \\
\hline
\end{tabular}

LBIs were hyperpolarized on alternate trials of $\mathrm{PD}$ stimulation and pairwise comparisons made ( $t$-test, repeated measures) between the number of PD-elicited action potentials on nonhyperpolarized and the immediately preceding hyperpolarized trials. Hyperpolarization significantly reduced the number of action potentials in a subset of the LBIs tested in each latency group. The average percent reduction in number of action potentials is given for these LBIs.

response to sensory stimulation and LBI depolarization were not in agreement (i.e., the contralateral DI and the ipsilateral VI), the synaptic potentials produced by sensory input were small.

\section{Connections between motor neurons}

The 8 types of longitudinal motor neurons contributing to dorsal bending are highly interconnected (Stuart, 1970; Ort et al., 1974; Granzow et al., 1985; Friesen, 1989). It is possible therefore that some of the coordination of motor neuron excitation and inhibition is attributable to these connections, rather than to inputs from the interneurons themselves. For example, the strong inhibitory connections from inhibitors to excitors of the same quadrant may be responsible for some of the inhibition of excitors when one of the P cells is stimulated. To determine whether this was the case, pairwise intracellular recordings were made from the ventral excitor cell 4 and its ipsilateral inhibitor cell 2 (Fig. 10A). PD was then stimulated $(10 \mathrm{~Hz}, 0.5 \mathrm{sec})$ with and, on alternate trials, without strong hyperpolarization of the inhibitor. Subtraction of the average with- and without-hyperpolarization responses showed that hyperpolarization of the inhibitor removed all of the inhibition, revealing an underlying excitatory response in the excitor. The same results were obtained for the dorsal excitor cell 3 and its ipsilateral inhibitor cell 1 when PV was stimulated (Fig. 10B).

\section{Discussion}

\section{Contribution of dorsal LBIs to local bending motor neuron} responses

Each pattern of sensory input to the local bending reflex is associated with a unique pattern of motor output (Lockery and Kristan, 1990). As a first step in understanding how this is achieved, we searched the ganglion for interneurons with input and output connections sufficient to produce dorsal local bending, that is, interneurons that were excited by at least one PD and in turn excited DEs. Each ganglion appeared to contain 17 such interneurons. Comparison of the time course of synaptic potentials in the interneurons (Fig. 2) and DE (Fig. $7 B-D$ ) in response to a train of $P$ cell impulses shows that these interneurons can account for the motor neuron response. The response of $\mathrm{DE}$ to a train of $\mathrm{P}$ cell impulses was characterized by a series of unitary, summating synaptic potentials. These could be produced by time-locked action potentials in the interneurons or by interneurons that release transmitter intraganglionically 
A Cell 115

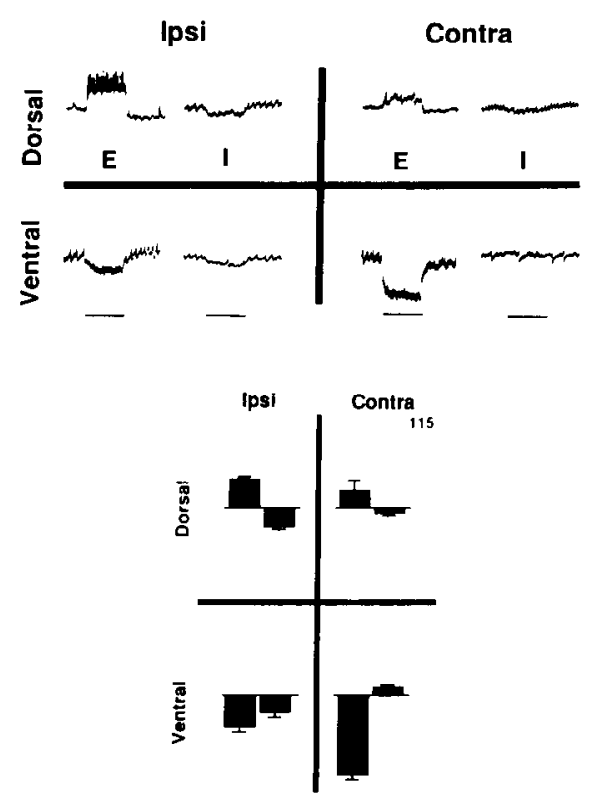

B Cell 125
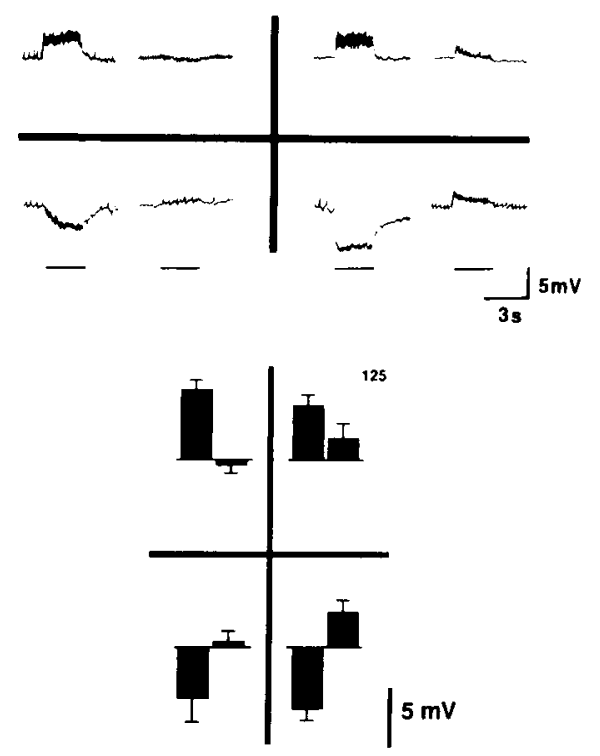

Figure 9. Effects on motor neurons of depolarizing individual interneurons. Upper panels, intracellular recordings from each of eight types of longitudinal motor neuron in response to depolarization $(2-4 \mathrm{nA}, 2.5 \mathrm{sec})$ of the indicated interneuron. Bars at the bottom indicate the duration of the current pulse. Each recording is shown in the quadrant location corresponding to the field of innervation of the motor neuron from which the recording was made. Within quadrants, the response of the excitatory motor neuron is shown on the left and the response of the inhibitory motor neuron is shown on the right. Lower panels, average peak synaptic potential from at least 3 experiments for the indicated interneuron. Abbreviations: $E$, excitatory motor neuron; $I$, inhibitory motor neuron. in the absence of action potentials, a common feature of interneurons in the leech (Thompson and Stent, 1976; Friesen, 1985; Granzow et al., 1985) and other invertebrates (Katz and Miledi, 1967; Burrows and Siegler, 1978). In the latter case, the timelocking of unitary synaptic potentials in the motor neuron would be the result of time-locked synaptic potentials in the interneurons in response to each $P$ cell impulse. Inspection of the response of each interneuron to $P$ cell impulse trains (Fig. 2) suggested that both mechanisms could play a role; with the exception of cell 159, action potentials were time-locked to the $P$ cell impulses, and all interneurons except cells 159 and 161 exhibited well-defined, time-locked synaptic potentials.

The present set of interneurons, though sufficient in principle to account for the time course of excitation of DE during dorsal local bending, cannot comprise the entire local bending network because additional interneurons must exist to provide the inhibition of DE and excitation of VE observed in response to ventral and lateral stimulation (Lockery and Kristan, 1990, Fig. 5). Such interneurons were, of course, systematically excluded by the selection criteria chosen in this initial study.

\section{Necessity of dorsal LBIs for dorsal local bending}

Many dorsal LBIs received substantial inputs from both PDs; inspection of Figure 8 shows that stimulation of a single PD activates between 14 and 16 dorsal LBIs. Thus, multiple parallel pathways exist between sensory and interneurons. On the assumption that each pathway was approximately equipotent, removing a single path by hyperpolarizing one dorsal LBI would have reduced the motor neuron response by about $7 \%$. The extracellular necessity tests typically produced $20-30 \%$ reductions in the number of action potentials in response to trains of $P$ cell impulses for each interneuron (Table 2). However, for technical reasons (see Materials and Methods), action potentials were not counted during the $P$ cell train, but only after it, that is, during the tail of the synaptic potential when the motor neuron was presumably returning to threshold and small changes in membrane potential could have had a disproportionately large effect on the number of action potentials. The intracellular necessity tests were complementary to the extracellular tests because the intracellular tests primarily examined the contribution of interneurons during the $P$ cell train itself. Hyperpolarization of individual interneurons reduced the motor neuron synaptic potential following the first or second, but not subsequent, $\mathbf{P}$ cell impulses in the stimulus train. Taken together, the evidence from intra- and extracellular necessity tests indicates that there exists a window during which hyperpolarizing current injection is ineffective in reducing transmitter release. One possibility is that there is a loss of control in the presynaptic terminal of the interneuron by the hyperpolarizing current during this window, due to the decrease in input resistance in the interneuron associated with synaptic input. The maximum decrease in input resistance would occur during the peak of the increase in synaptic conductance, that is, at the height of the synaptic potential in the interneuron and therefore near the peak of the motor neuron synaptic potential as well. An alternative possibility is that the relative contribution of the interneurons subjected to the necessity test was reduced in the later stage of the $P$ cell impulse train as the effect of other, untested interneurons became a greater proportion of the total response. Shifts in the relative contribution of interneurons could be due to differential facilitation of either sensory to interneuron (Fig. 2) or interneuron to motor neuron synapses, or to differences in the number of $P$ cell impulses required to bring some interneurons to the threshold for transmitter release.

The modest effect of removing individual dorsal LBIs from the circuit is consistent with results of similar experiments in other systems involving multiple interneuronal pathways (Jellies and Larimer, 1986; Nagayama and Hisada, 1987; I Iensler, 1988; Laurent and Burrows, 1988). Nevertheless, it raises the possibility that other, as yet undiscovered, interneurons contribute to the synaptic potential in DE; however, we believe this is unlikely since we undertook an exhaustive search of many ganglia. Additional pathways could be provided by the processes of dorsal LBIs whose somata lie in adjacent ganglia (which were 
A

control

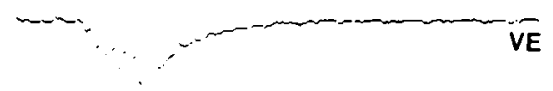

VI hyperpolarized ( 9 nA)

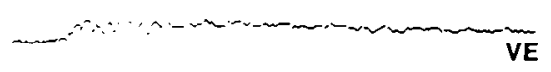

VE

difference

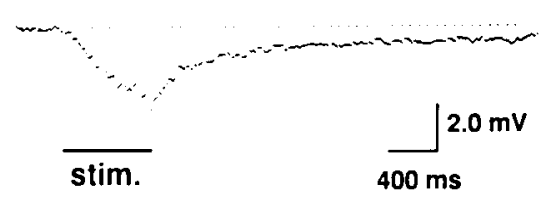

B

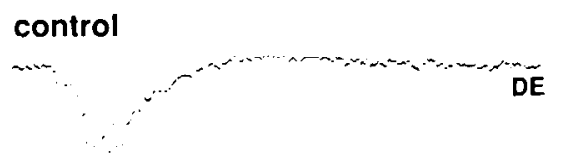

DI hyperpolarized (5 nA)

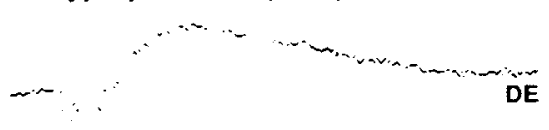

difference

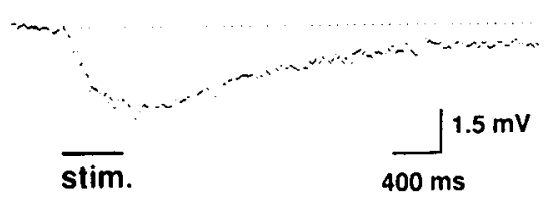

Figure 10. Effect of hyperpolarization of inhibitory motor neurons on the response of excitatory motor neurons to PD stimulation. A, Recording from VE (ipsilateral to PD) with and without hyperpolarization of the ipsilateral VI. $B$, Recording of DE (ipsilateral to PD), with and without hyperpolarization of the ipsilateral DI. In each panel, the top trace (control) is the average digitized recording from the excitatory motor neuron $(A$, cell $4 ; B$, cell 3 ) during elicitation of a train of impulses in PD. The duration of the stimulus train $(10 \mathrm{~Hz}$, $0.5 \mathrm{sec}$ ) is shown by the horizontal bar. The middle race (hyperpolarized) is the same, except that the inhibitory motor neuron that innervates the same quadrant was hyperpolarized. The lower trace (difference) is the result of subtracting the middle trace from the top trace. Control and hyperpolarized sweeps were recorded on alternated trials. Number of sweeps contributing to each average: $A, 15 ; B, 10$. Abbreviations: $c$, contralateral; $i$, ipsilateral. removed in dissection) if these processes had local $\mathrm{P}$ cell inputs and motor neuron outputs. The number of pathways potentially provided by adjacent ganglia is large; a single ganglion's complement of LBIs sends a total of 28 axons to the interganglionic connectives and presumably to the adjacent ganglia (Fig. 3). Processes isolated from their somata can remain functional in the leech (Carbonetto and Muller, 1977).

\section{Cells 115 and 125}

A summary of the input and output connections of cells 115 and 125 , together with previously established connections among motor neurons, is shown in Figure 11. The coordinated excitation and inhibition of motor neurons produced by cells 115 and 125 might be explained by connections of the appropriate sign from interneurons to motor neurons or by connections to selected motor neurons together with lateral connections among the motor neurons themselves. For example, in the case of cell 115 , some or all of the inhibition of the ipsilateral VE is attributable to an inhibitory connection from the cell 115 to the contralateral VE together with the electrical connection between VEs. Similarly, for cell 125 , some or all of the inhibition of the contralateral VE by cell 125 is attributable to excitation of the contralateral VI which inhibits VE. Indeed, lateral inhibition at the motor neuron level appears to play an important role in determining the response to PD stimulation (Fig. 10). It is clear, however, that connections between motor neurons cannot explain all aspects of the cell 115 and 125 output patterns. For instance, cell 115 produces little or no excitation of the VIs, yet both VEs are strongly inhibited by this interneuron. Thus, it appears that a mixture of interneuron-motor neuron and motor neuron-motor neuron connections could contribute to shaping the output patterns.

\section{Production of local bending motor output patterns}

Inspection of the input and output connections of cells 115 and 125 suggests that the pattern of motor output produced by stimulation of a single PD (Lockery and Kristan, 1990, Fig. 4A) is the sum of appropriate and inappropriate interneuronal effects. Stimulation of the left PD excites both the left and right cell 115 and the left and right cell 125. The DEs and VEs receive appropriate inputs from all 4 interneurons (i.e., excitation and inhibition, respectively), while the inhibitors are excited by some interneurons and inhibited by others. For instance, the DIs receive conflicting excitatory and inhibitory inputs from the left and right cell 125 , and the left VI receives conflicting inputs from the left cell 115 and 125 . Similar conflicts must occur in response to paired stimulation of the left and right PD (Lockery and Kristan, 1990, Fig. 5A) because this stimulation pattern activates the same 4 interneurons.

The fact that most dorsal LBIs received excitatory input from at least one ventral $P$ cell (PV) means that motor output patterns produced by stimulation involving ventral input are also produced by summation of appropriate and inappropriate effects. Stimulation of a single PV produces net inhibition of ipsi- and contralateral DEs (Lockery and Kristan, 1990, Fig. 4B), despite the fact that most of the dorsal LBIs, which excite DEs, are activated by this stimulus. While activation of dorsal LBIs appears to be counterproductive in ventral local bending, it can contribute positively to lateral local bending (the response to ipsilateral PD and PV stimulation), which produces net excitation of DEs and inhibition of VEs on the stimulated side (Lockery and Kristan, 1990, Fig. 5C).

\section{Latencies of interneurons and motor neurons}

Previously reported monosynaptic latencies for intraganglionic conncctions in the lecch range from 2 to $4 \mathrm{msec}$ (Nicholls and Purves, 1970; Nicholls and Wallace, 1978). The shortest synaptic latencies in motor neurons were about $6 \mathrm{msec}$, consistent with a disynaptic pathway from PD. Since the latency of the intermediate group of interneurons was about $3 \mathrm{msec}$, it is possible that these cells mediate the short-latency motor neuron synaptic potentials. By contrast, it is unlikely that the longlatency group of interneurons contributes to the initial rise of synaptic potentials in the short-latency motor neurons since the 
A Cell 115

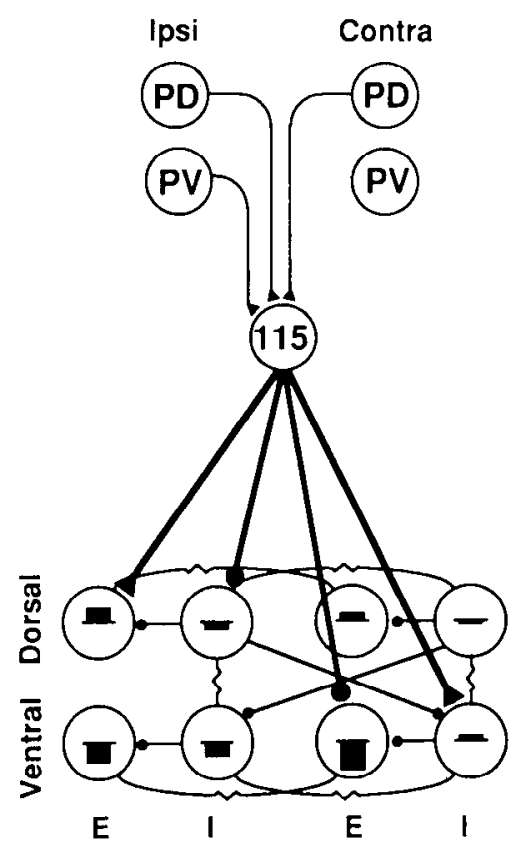

B Cell 125

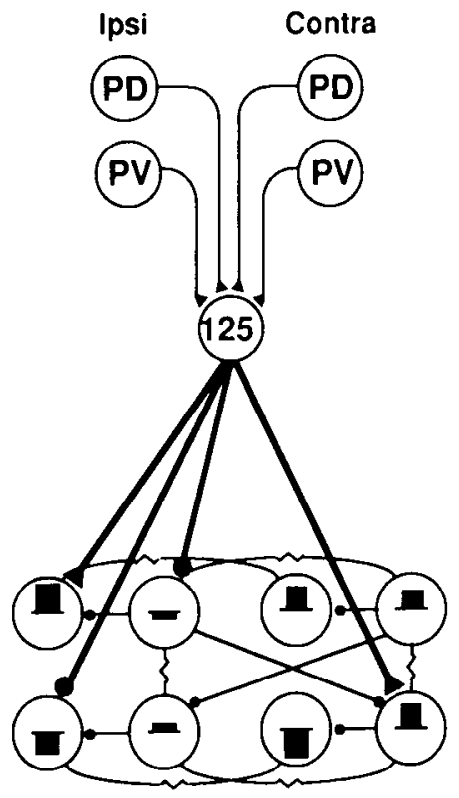

Figure 11. Summary of input and output connections of 2 local bending interneurons. The location of each sensory and motor neuron corresponds to its field of innervation. Connections are functional and not necessarily direct. Lateral connections among motor neurons are also shown. The effect of depolarizing each interneuron is indicated by the bars inside the motor neurons. For simplicity, connections from interneurons to motor neurons have been omitted where the required effects could be mediated by lateral connections among motor neurons. Ipsilateral and contralateral are with reference to the soma of the interneuron. Symbols are given in the key. Abbreviations: $E$, excitatory motor neuron; $I$, inhibitory motor neuron.

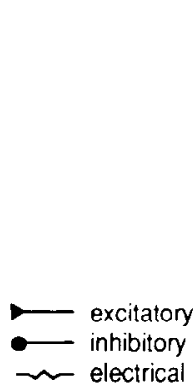
(n)

latencies of these 2 groups were roughly equivalent. However, the long-latency interneurons could still contribute to the peak and tail of the synaptic potential in the short-latency motor neurons which reaches a peak in about $15 \mathrm{msec}$, and is tens of milliseconds in duration.

The longest synaptic latencies between $P$ cells and motor neurons were equal to approximately 3 monosynaptic latencies, suggesting a trisynaptic pathway from $\mathrm{PD}$. It is possible that the long-latency group of interneurons contributes directly to the synaptic potentials in the long-latency motor neurons since there was the equivalent of a single monosynaptic delay between these groups. It is less likely that the intermediate group of interneurons contributes directly to the synaptic potentials of the longlatency motor neurons, since there appear to be 2 synaptic delays between PD and these motor cells. However, such a contribution cannot be ruled out, since synaptic release in the leech, being often independent of action potentials (Thompson and Stent, 1976; Granzow et al., 1985), can be subject to longer conduction times than might otherwise be anticipated (Burrows and Siegler, 1978; Friesen, 1985).

\section{Parallel and serial connections in the local bending network}

The connectivity of cells 115 and 125 , together with related data from other interneurons, suggests that the basic unit of the local bending network is an element that receives inputs from left and right, dorsal and ventral sensory cells and has substantial connections to left and right, excitatory and inhibitory longitudinal motor neurons. However, the present data are insufficient to determine whether the interneurons are arranged in a mostly parallel network or one that combines parallel and serial connections.

The 2 possibilities are distinguished by the way in which each accounts for the latency from the $P$ cell to the long-latency group of motor neurons, as shown in Figure 12. In an exclusively parallel circuit with no interconnections among the interneurons (Fig. 12A), the short and intermediate latency interneurons would affect motor neurons by lateral connection among motor neurons or by direct but intrinsically slow connections from interneurons to motor neurons (Burrows and Siegler, 1978; Friesen, 1985). Long-latency interneurons would contribute to the prolonged motor neuron response, after the initial rising phase. By contrast, in a mixed parallel-serial circuit (Fig. 12B), interneurons would be arranged in 2 tiers: the short- and intermediatelatency interneurons together in the first tier (since there do not appear to be forward connections between these groups) and the long-latency interneurons in the second. In this case, the longlatency motor neurons receive their inputs from other motor ncurons, as before, or from long-latency interneurons. The 2 possibilities are, of course, compatible. A combination of single and multiple interneuronal tiers has been observed in other systems (Hawkins et al., 1981; Jellies and Larimer, 1985; Burrows et al., 1988).

While a uniformly parallel model is conceptually simple, it requires the same interneuron to have multiple latencies to motor neurons. This might be possible for a nonspiking interneuron if the connections to motor neurons were mediated by dendrites of different electronic lengths, and hence intrinsic delays, though we have no direct evidence for this. The combined parallelserial arrangement does not entail the same difficulty; however, this scheme requires interneuron-interneuron connections which have not yet been found.

\section{Feature detection and distributed processing}

$\Lambda$ nalysis of the input-output relations of local bending indicated that the reflex can distinguish different patterns of paired $P$ cell stimulation, i.e., it produces different behavioral outputs to different combinations of $\mathbf{P}$ cell stimuli (Lockery and Kristan, 1990). Hypothetical circuits that account for this capacity are of 2 main types and make different predictions regarding input connections. Under a dedicated neuron or "feature detector" hypothesis (Ewert, 1987), each dorsal LBI would respond to a specific sensory neuron or pair of sensory neurons. A left lateral 
A. Parallel

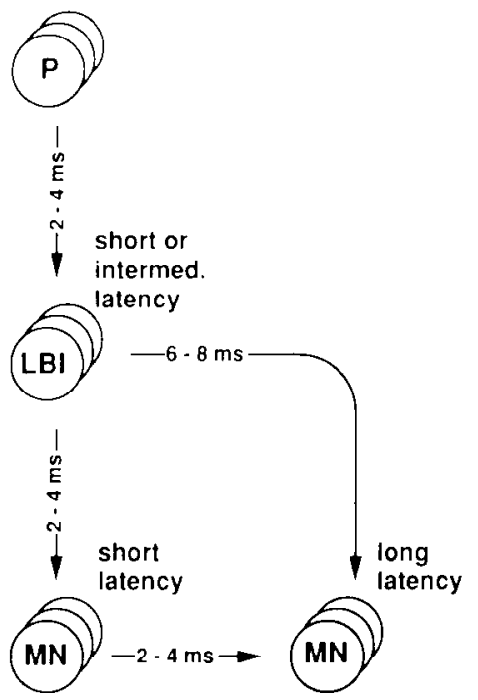

B. Parallel and serial

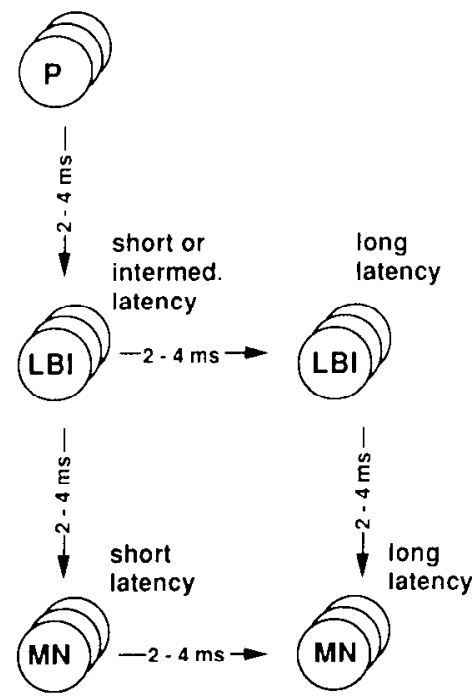

Figure 12. Two arrangements of local bending interneurons. In $A$, interneurons are arranged in parallel and input to the long-latency motor neurons is via intrinsically slow connections from interneurons (or connections between motor neurons). In $B$, interneurons are arranged in combined parallel and serial fashion and input to the long-latency motor neurons is via a second tier of interneurons (or connections between motor neurons). bending interneuron, for example, would have connections only from the left PD and PV, a dorsal bending interneuron would have connections from only the right and left PD, and so on for the other paired $P$ cell patterns that the system specifically detects. Under a "distributed processing" hypothesis, interneurons could receive inputs from 1-4 sensory cells, no interneuron would be specific for a given $P$ cell pair, and detection of particular stimuli would be achieved by the set of interneurons as a whole.

Examination of the inputs to the dorsal LBIs strongly favors the distributed processing hypothesis. The only interneuron consistent with the feature detector model is cell 161 , which appears to receive input only from the ipsilateral PD. All other identified cells had substantial inputs from all $4 \mathrm{P}$ cells, implying that each interneuron responds, in some degree, to all patterns of sensory input; none appears to have input connections as required by the feature detector model for the detection of particular P cell pairs.

The fact that most interneurons received input from all $4 \mathrm{P}$ cells raises the question of whether the present set of interneurons can distinguish one sensory input pattern from another. In the extreme case, where each interneuron receives a connection of identical strength from cach sensory cell, the system could determine the number of active $P$ cells, but not which $P$ cells were active. However, with sufficient variation in the strengths of $P$ cell-interneuron connections, a distributed representation of sensory input would emerge in which different input patterns would produce different levels of interneuron activation, despite the fact that an individual interneuron responds to all 4 sensory cells. Inspection of the variability of $\mathrm{P}$ cell-interneuron connection strengths (Fig. $8 B$ ) suggests that the local bending network employs such a distributed representation. If so, then the conflicts between output effects of particular interneurons is a natural consequence of this method of information processing because each interneuron participates in the production of multiple, and incompatible, output patterns.

\section{Models of distributed processing}

The evidence presented here suggests that each dorsal LBI participates in the detection of several patterns of sensory input and contributes to a variety of motor output patterns. Thus, responsibility for translating each input pattern into the appropriate pattern of motor output cannot be localized to particular interneurons; instead, it appears to be distributed across many interneurons. While such a model is conceptually plausible, it remains to be shown whether it can be made to function in practice. At issue is how the system links a distributed representation of sensory input to particular patterns of motor output. Specifically, can a single set of interneuron-motor neuron connections be found such that the entire input-output function of the reflex is produced by interneurons that receive left and right, dorsal and ventral $\mathrm{P}$ cell inputs? It is not immediately obvious that such a set of connections exists; however, since the inputoutput function of the reflex is quantitatively well defined (Lockery and Kristan, 1990), neural network modeling techniques that predict interneuronal connectivity from input-output information (Lehky and Sejnowski, 1988; Zipser and Anderson, 1988) can be used to answer this question. Preliminary results from one such study indicate that it is indeed possible to find such a set of connections (Lockery et al., 1989). In fact, a great many such sets exist, raising the interesting possibility that identical behaviors could be produced by physiologically distinct neural circuits.

\section{Appendix}

\section{Distinguishing features of dorsal LBls}

Cell 115 was found in the dorsal anterior packet in the region defined by map locations 105-106-114-115 (Fig. 4). It had a soma diameter of $25-35 \mu \mathrm{m}$ and an initial segment that was flat and broad. A single axon projected posteriorly, leaving the ganglion via the contralateral connective. Unitary EPSPs from PD onto cell 115 usually produced a single action potential (not shown). Trains of $P$ cell impulses caused individual EPSPs that underwent facilitation and summation. Cell 115 has been previously identified in connection with the swimming pattern generator (Friesen, 1989).

Cell 125 was found in the dorsal anterior packet along the posterior packet margin at map location 122-126. It had a cell body of $15-25 \mu \mathrm{m}$ that, in desheathed preparations, often lay under cell 101. Cell 125 had a short initial segment that gave 
rise to a single axon in the ipsilateral, posterior connective. It received a unitary EPSP from the $P$ cell with a latency $2 \mathrm{msec}$ shorter than the latency to cell 115 and often fired a single action potential. Trains of $\mathrm{P}$ cell action potentials elicited trains of EPSPs that summated but did not facilitate.

Cell 157 generally was found in the center of the lateral ventral packet, near the mechanosensory neurons. It had a small soma of $20-30 \mu \mathrm{m}$, with axons projecting into the anterior and posterior trunks of the contralateral connectives. Its initial segment was much fincr than that of cell 169 , the other ventral interneuron with 2 contralaterally situated axons. Unitary EPSPs in cell 157 occurred with one of the longest latencies and regularly caused single action potentials. Trains of $\mathbf{P}$ cell impulses produced trains of discrete EPSPs that were characteristically larger at the beginning and ends of the train. Action potentials in cell 157 , although large, were smaller than those of cell 162, which had larger unitary EPSP.

Cell 159 was found in the same general region of the ganglion as cell 157. It had a soma of approximately $20-30 \mu \mathrm{m}$ and was unique among cells on the ventral surface in having a single fine axon that exited the ganglion in the posterior ipsilateral connective. Unitary EPSPs that occurred had a long latency, and although these were quite small, they usually produced action potentials. Trains of $P$ cell impulses produced a characteristically ragged EPSP composed of small, individual EPSPs that facilitated and showed moderate summation. This was more readily apparent when the cell was strongly hyperpolarized. The action potentials and EPSPs in this interneuron were consistently among the smallest.

Cell 161 was usually found along the posterior margin of the anterior lateral packet on the ventral surface, or less often, just across the packet margin in the posterior lateral packet. Thus, it was found anywhere in the map region defined by cell locations 161-162-62-65. Like cell 162, cell 161 had a soma diameter of 15-25 $\mu \mathrm{m}$ and axons in both ipsilateral connectives. However, in contrast to cell 162, the fine processes of cell 161 projected largely to the medial side of the axons. Trains of $P$ cell impulses produced trains of decrementing EPSPs with a characteristic plateau between the first and second EPSPs in the train. Occasional spontaneous IPSPs were also seen and action potentials were very small.

Cell 162 was found in approximately the same location as cell 161 and had a soma of approximately the same size (15$25 \mu \mathrm{m}$ ) with an axon in the ipsilateral trunks of the anterior and posterior connectives. Unitary EPSPs from PD usually produced action potentials that were much larger than those of cell 161. Trains of impulses produced trains of discrete EPSPs that facilitated then decremented without the plateau typical of cell 161 's PSPs. Cell 161 and 162 were occasionally found on the same side of a given ganglion, justifying the distinction between these 2 rather similar cell types.

Cell 169 was most often found among a cluster of small cells at map locations 166-170, but in preparations from which the larger somata had been removed, it was sometimes found more laterally. This cell had a soma of $20-30 \mu \mathrm{m}$ and was distinguished by a thick initial segment giving rise to 2 axons that entered the anterior and posterior contralateral connectives. Physiologically, cell 169 resembled cell 159 in many respects. Its small unitary EPSPs had a long latency, were slowly rising, and often accompanied by action potentials. Its EPSP in response to trains of $P$ cell impulses was ragged, much like that of cell 159. Its action potentials were also small but had a more pronounced undershoot than those of cell 159 .

Cell 212 was found in the left and right posterior corners of the central packet (map locations 202 and 212), and sometimes in the upper corners of the posterior packet. It had a large soma of $30-40 \mu \mathrm{m}$ and a distinctly broad initial segment. Its unitary EPSPs were among the largest of the dorsal LBIs. P cell trains produced nonsummating EPSPs that facilitated then decremented. Action potentials were intermediate in size.

Cell 218 was typically found in the anterioventral central packet just lateral to the most anterior Retzius cell. In some preparations, it was found at map location 222; more rarely, it occurred in the lateral anterior packet (map location 166). With a soma diameter of $30-40 \mu \mathrm{m}$, it was one of the largest of the LBIs. Cell 218 appeared to be unpaired; only one example was found in any ganglion, despite explicit searches for a homolog across the midline in 15 preparations. The morphology of 218 was reminiscent of another unpaired neuron, the $\mathrm{H}$ cell (Petersen, 1985) with axons in the right and left trunks of both connectives. Unitary EPSPs from the P cell had the shortest latency and showed little or no facilitation or summation. Action potentials in 218 were very small and difficult to detect against the background of larger and more frequent spontaneous EPSPs. In addition to exciting cell 3 , cell 218 excited another DE, cell 107.

\section{References}

Burrows M, Siegler MVS (1978) Graded synaptic transmission between local interneurones and motor neurones in the metathoracic ganglion of the locust. J Physiol (Lond) 285:231-255.

Burrows M, Laurent GJ, Field LH (1988) Proprioceptive inputs to nonspiking local interneurons contribute to local reflexes of a locust hindleg. J Neurosci 8:3085-3093.

Carbonetto SJ, Muller KJ (1977) A regenerating neurone in the leech can form an electrical synapse on its severed axon segment. Nature $267: 450-452$.

Ewert J-P (1987) Neuroethology of releasing mechanisms: prey-catching in toads. Behav Brain Sci 10:337-405.

Friesen WO (1985) Neuronal control of leech swimming movements: interactions between cell 60 and previously described oscillator neurons. J Comp Physiol 156:231-242.

Friesen WO (1989) Neuronal control of leech swimming movements. In: Neuronal and cellular oscillators (Jacklet JW, ed). New York: Marcel Dekker.

Granzow B, Friesen WO, Kristan WB Jr (1985) Physiological and morphological analysis of synaptic transmission between leech motor neurons. J Neurosci 5:2035-2050.

Hawkins RD, Castellucci VF, Kandel ER (1981) Interneurons involved in mediation and modulation of gill-withdrawal reflex in Aplysia. I. Identification and characterization. J Neurophysiol 45:304314.

Hensler K (1988) Intersegmental interneurons involved in the control of head movements in crickets. J Comp Physiol 162:111-126.

Jellies J, Larimer JL (1985) Synaptic interactions between neurons involved in the production of abdominal posture in crayfish. J Comp Physiol 156:861-873.

Jellies J, Larimer JL (1986) Activity of crayfish abdominal-positioning interneurones during spontaneous and sensory-evoked movements. J Exp Biol 120:173-188.

Katz B, Miledi R (1967) Synaptic transmission in the absence of nerve impulses. J Physiol (Lond) 192:407-436.

Kristan WB Jr (1982) Sensory and motor neurons responsible for the local bending response in leeches. J Exp Biol 96:161-180.

Kristan WB Jr, Stent GS, Ort CA (1974) Neuronal control of swimming in the medicinal leech. I. Dynamics of the swimming rhythm. J Comp Physiol 94:97-119.

Kristan WB Jr, McGirr SJ, Simpson GV (1982) Behavioral and me- 
chanosensory neurone responses to skin stimulation in leeches. J Exp Biol 96:143-160.

Laurent GJ, Burrows M (1988) Direct excitation of nonspiking local interneurones by exteroceptors underlies tactile reflexes in the locust. J Comp Physiol 162:563-572.

Lehky SR, Sejnowski TJ (1988) Network model of shape-from-shading: neural function arises from both receptive and projective fields. Nature 333:452-454.

Lockery SR, Kristan WB Jr (1990) Distributed processing of sensory information in the leech. I. Input-output relations of the local bending reflex. J Neurosci 10:1811-1815.

Lockery SR, Wittenberg G, Kristan WB Jr, Cottrell G (1989) Function of identified interneurons in the leech elucidated using neural networks trained by back-propagation. Nature 340:468-471.

Muller KJ, Nicholls JG, Stent GS (1981) Neurobiology of the leech. Cold Spring Harbor, NY: Cold Spring Harbor Laboratory.

Nagayama T, Hisada M (1987) Opposing parallel connections through crayfish local nonspiking interneurons. J Comp Neurol 257:347-358.

Nicholls JG, Purves D (1970) Monosynaptic chemical and electrical connexions between sensory and motor cells in the central nervous system of the leech. J Physiol (Lond) 209:647-667.

Nicholls JG, Wallace BG (1978) Quantal analysis of transmitter release at an inhibitory synapse in the central nervous system of the leech. J Physiol (Lond) 281:157-170.

Nusbaum MP, Friesen WO, Kristan WB Jr, Pearce RA (1987) Neural mechanisms generating the leech swimming rhythm: swim-initiator neurons excite the network of swim oscillator neurons. J Comp Physiol 161:355-366.

Ort CA, Kristan WB Jr, Stent GS (1974) Neuronal control of swimming in the medicinal leech. II. Identification and connections of motor neurones. J Comp Physiol 94:121-154.

Petersen E (1985) Visual interneurons in the leech brain. III. The unpaired H cell. J Comp Physiol 156:719-727.

Selverston AI, Russell DF, Miller JP (1976) The stomatogastric nervous system: structure and function of a small neural network. Prog Neurobiol 7:215-290.

Stuart AE (1970) Physiological and morphological properties of motoneurones in the central nervous system of the leech.J Physiol (Lond) 209:627-646.

Susswein AJ, Byrne JH (1988) Identification and characterization of neurons initiating patterned neural activity in the buccal ganglia of Aplysia. J Neurosci 8:2049-2061.

Thompson WJ, Stent GS (1976) Neuronal control of heartbeat in the medicinal leech. J Comp Physiol 111:309-333.

Weeks JC (1982) Synaptic basis of swim initiation in the leech. II. A pattern-generating neuron (cell 208) which mediates motor effects of swim-initiating neurons. J Comp Physiol A 148:265-279.

Zipser D, Andersen RA (1988) A back-propagation programmed network that simulates response properties of a subset of posterior parietal neurons. Nature 331:679-684. 